\title{
Assessing the Key Attributes of Low Utilization of Mammography Screening and Breast-self Exam among African-American Women
}

\author{
Rupak Chowdhury, Nganwa David, Asseged Bogale, Shami Nandy, T. Habtemariam, Berhanu Tameru \\ Center for Computational Epidemiology, Bioinformatics and Risk Analysis (CCEBRA), College of Veterinary Medicine, Nursing and Allied Health (CVMNAH), \\ Tuskegee University, Tuskegee, AL 36088, USA. \\ $\square$ Corresponding author: tameru@mytu.tuskegee.edu \\ (1) Ivyspring International Publisher. Reproduction is permitted for personal, noncommercial use, provided that the article is in whole, unmodified, and properly cited. See \\ http://ivyspring.com/terms for terms and conditions.
}

Received: 2015.06.16; Accepted: 2015.11.10; Published: 2016.02.12

\begin{abstract}
PURPOSE: African-American (AA) women living in four Black Belt Counties (BBC) of Alabama; consisting of Barbour, Macon, Green and Wilcox are known to have lower mammogram utilization and breast self-exam rates when compared to their white female counterparts. The influence of socioeconomic and demographic factors on these disparities has not been clearly defined so far. Our study was designed to determine whether these observed disparities can be predicted with the socioeconomic and other demographic attributes. METHODS: Health Disparity Questionnaires data $(n=516)$ for BBC of Alabama was analyzed using a logistic regression model to examine the association of breast cancer screening rates and breast self-exam with income, the level of education, family doctor, type of health insurance, obesity, and age. RESULTS: Income, education, family doctor, age and health insurance were independent predictors for the low utilization rate of mammography and breast self-exam (BSE). CONCLUSION: Improving socioeconomic conditions such as level of education and availability of health care are essential to increase the rates of breast cancer screening test and breast self-exam in the BBC of Alabama.
\end{abstract}

Key words: African-American (AA) women, breast cancer screening

\section{Introduction}

Breast cancer is a neoplastic proliferation of breast tissue (ducts and glandular structure). This neoplastic proliferation can be limited to its site of origin (either ducts or glands), can invade surrounding tissues, and can also metastasize to distant parts of the body (1). The duration of time needed for cancer to metastasize and bring on ultimate death depends on how extensively it was spread at the time of first diagnosis (1). Around $6 \%$ of patients with breast cancer have metastatic disease at the time of diagnosis; and despite all recent developments in treatment modalities, the 5-year survival rate for metastatic breast cancer (MBC) patients is only $26 \%$ (2). These statistics signify the need for a different approach towards breast cancer management and as such the method of early diagnosis can be of immense im- portance. To date, no definitive ways have been found to prevent breast cancer, and this is where various screening tools can play a vital role (3).

A Mammogram is one such screening tool that is, in fact, a low dose x-ray that can visualize internal structure of the breast. Modern mammography can detect the presence of cancerous growth in the breasts even before the development of any sign or symptom of cancer (4). Hence, the primary purpose of mammography screening for breast cancer is early detection and appropriate treatment that may lead to prolongation of survival rate for breast cancer patients (3). According to National Cancer Institute recommendations, women aged 50 and above should be screened for breast cancer with a mammogram every 1-2 years (5). 
Although it plays a small role in the detection of breast cancer, another way by which women can increase their breast cancer awareness is by doing breast self-examination (BSE) (6). This BSE can be done either by just knowing the natural look and feel of the breasts and then feeling for any changes (i.e. breast awareness) or by the choice of a step-by-step approach and specific schedules (like once in a month) (7). As the goal of breast health is to report any breast changes to a health care professional as soon as possible, doing a regular breast-self exam (BSE) can make a woman aware of her healthy breasts so that she can more readily find any changes worth reporting (like a lump or swelling, breast skin irritation or dimpling, pain or retraction (turning inward) of the nipple, breast skin redness or scaling, or a discharge other than breast milk (6).

Among the various disparities in breast cancer, the disproportionately high rate of mortality among African American breast cancer patients is a major concern (9). Previous studies suggest that African American women in the United States have increased mortality from breast cancer compared to White women(9). The disparity arises in part, from infrequent screening practices in African American women (11) but cannot be solely attributed to that cause. Some studies $(10,11)$ have identified socioeconomic and health system-related characteristics that are barriers to breast cancer screening. Well-established obstacles to screening include individual characteristics such as low income and lower educational attainment (8). Recently it has been reported in several studies that medically uninsured women have less cancer screening and higher breast cancer rates $(10,11)$. Also, the health insurance (11) status may work in complex ways to influence access to appropriate preventive services. Understanding the mechanisms of these interactions will help in formulating interventions that can reduce disparities in health care by increasing screening rates for breast cancer (13). Then again, the utilization of mammography has been particularly low among the defined high-risk population, those who have not been targeted aggressively to increase their compliance with screening recommendations (14).

In Alabama, existing disparities in heart disease and cancer mortality are most evident in rural black belt counties (12). High rates of death from breast cancer in these counties are due, in part, to the infrequent utilization of screening tests $(15,17)$. Several factors have been implicated in these disproportionately high rates of breast cancer deaths and infrequent use of screening tests (18). It's hard to deliver preventive care such as breast cancer screening in rural areas. However, the listing is incomplete regarding the fac- tors that hinder breast cancer screening in rural Alabama (20). The main purpose of this study is to determine if significant correlations exist between disparities in breast cancer screening and breast-self exam (BSE) and the following variables: health insurance, the ability to afford a family doctor, socioeconomic status (income, education), age (postmenopausal women), and existing co-morbidity (obesity). Our hypothesis was that various socioeconomic and demographic attributes are directly correlated with use of mammography and breast-self exam (BSE) among African American women in rural Alabama.

\section{Methods}

\section{Study Population and Data Collection:}

A Comprehensive Health Survey Questionnaire was developed to carry out a baseline survey in black belt counties of Alabama. Informed consent forms were developed to ensure privacy and the Tuskegee University IRB committee reviewed and approved.

The study sample constitutes 800 randomly selected African American men and women in total (i.e. 200 from each of the four randomly selected BBC counties of Alabama; namely Barbour, Macon, Greene, and Wilcox). Questionnaires survey was mailed to 200 participants selected from each of the four counties to collect data on health disparities. The questionnaire had fifty-eight questions, sub-divided into biometry, socio-economic status, existing health states and other psychosocial factors, which were designed to identify differences in the availability and use of health care among the study sample. The focus of this study to assess the key attributes of low utilization of Mammography screening and breast-self exam among African-American women in four black belt counties of Alabama.

In total, $516(64.42 \%)$ women completed the questionnaire in full. Consistent with National Cancer Institute guidelines (NCI, 1977), 352 African-American women aged 50 years and older were included in this study. Women who had BMI $\geq 30$ were categorized as obese, and age $\geq 50$ were categorized as postmenopausal. As indicated above, the study variable is the use of Mammogram, breast-self exam and participants were inquired if they ever have had any Mammogram and ever did any breast-self exam.

For any affirmative responses, the date of the most recent tests, within the last 1-3 years (The United States Preventive service task force recommendation) was recorded (27). Various socioeconomic traits and other attributes including the level of education, family income, health insurance, existing health conditions (obesity), Age, and Affordability of the family doctor were additionally recorded. For analyzes, a 
two-stage statistical process was applied. In the first stage, the variables were assessed as appropriate, using Chi-square statistic. In the second stage, factors were evaluated using unconditional multiple logistic regression (SAS), applying a backward stepwise model with removal based on the likelihood-ratio statistic until all $p$-values were $\leq 0.05$. The overall model fit was tested using the Wald statistic.

\section{Results}

Table 2, 3 depict summarized survey result using Chi square analysis. The result of the multiple logistic regressions as obtained from the model in which all the variables were evaluated simultaneously are presented in Table 4.

The analysis reveals that mammography and BSE were related to women's education, family income, health insurance, health condition, affordability to visit doctor and Age $\geq 50$ (Table 2). In short, women who received mammography or reported BSE had higher education, higher family income, could afford to visit a doctor, and were less likely to be uninsured. As expected, BSE had the association with physician visits $(\mathrm{P}<0.0001)$. On the other hand, women aged 50 years and older reported less mammogram than $<50$ years age group $(P<0.0001)$ and age $\geq 50$ group reported less BSE $(\mathrm{P}<0.001)$. Likewise, obese women
(BMI $\geq 30$ ) reported less mammogram and BSE when compared to non-obese women $(\mathrm{BMI}<30)(\mathrm{P}<0.001)$.

\section{Adjusted Odd Ratio}

Family income, health insurance, age were all important predictors of BSE and mammography (Table 4). Women who had health insurance coverage were more likely to receive a mammogram compared to uninsured women (No vs. Yes; OR=0.779 CI 0.453-0.834). Health Insurance was also a predictor for a breast-self exam (No vs. Yes; $\mathrm{OR}=0.306 \mathrm{CI}$ $0.173-0.542$ ). Table 4 showed that as yearly family income level increase, women are more likely to receive a mammogram and BSE. Women age $\geq 50$ group was the predictor for BSE (OR=0.57, CI 0.384-0.765). Women age $\geq 50$ was also predictor for Mammogram (OR=0.455, CI 0.304-0.723).

Table 1: Baseline Sample characteristics

\begin{tabular}{lll}
\hline Variables & N or Mean $( \pm$ SD $)$ & P-value \\
\hline Age & $42.34( \pm 13.7)$ & $<.0001$ \\
BMI & $29.4( \pm 7.70)$ & $<.0001$ \\
Breast Exam & & $<.0001$ \\
Yes & 163 & \\
No & 352 & \\
Mammograms & & $<.0001$ \\
1 to 3 & 150 & \\
4 or more & 11 & \\
None & 355 & \\
\hline
\end{tabular}

Table 2: The association between selected socioeconomic variables and use of Mammogram in four BBC (Barbour, Green, Macon and Wilcox) of Alabama.

\begin{tabular}{|c|c|c|c|c|c|}
\hline \multirow[t]{2}{*}{ Variable } & \multicolumn{5}{|c|}{ Use mammogram } \\
\hline & yes & no & $\%$ not using & OR $(95 \% \mathrm{CI})$ & $\chi^{2}$ (p-value) \\
\hline \multicolumn{6}{|l|}{ Education } \\
\hline - Grades 1 through 8 (elementary) & 2 & 7 & $77.78 \%$ & $0.3516(0.157-0.4055)$ & $<.0001$ \\
\hline Grades 9 through 11 (some high school) & 15 & 34 & $69.39 \%$ & $0.2545(0.1044-0.2727)$ & $<.001$ \\
\hline - Grade 12 or GED (high school graduate) & 62 & 78 & $55.71 \%$ & $1.2329(1.1040-1.2716)$ & $<.0001$ \\
\hline $\begin{array}{l}\text { - College } 1 \text { year to } 3 \text { years (some college or } \\
\text { technical school) }\end{array}$ & 90 & 77 & $46.11 \%$ & $1.1815(1.0826-2.2152)$ & $<.0001$ \\
\hline College 4 years or more (college graduate) & 65 & 29 & $30.85 \%$ & $1.735(1.1318-2.3457)$ & $<.0001$ \\
\hline Graduate school & 21 & 19 & $47.50 \%$ & $1.724(1.1164-3.3125)$ & $<.0001$ \\
\hline \multicolumn{6}{|l|}{ Family income } \\
\hline$\$ 9,999$ or under & 42 & 57 & $57.58 \%$ & $0.507(0.1736-0.32)$ & $<.0001$ \\
\hline$\$ 10,000$ to 14,999 & 34 & 49 & $59.03 \%$ & $0.954(0.445-2.023)$ & $<.0001$ \\
\hline$\$ 15,000$ to 19,999 & 26 & 24 & $48.00 \%$ & $1.770(1.650-3.718)$ & $<.0001$ \\
\hline$\$ 20,000$ to 24,999 & 25 & 22 & $46.81 \%$ & $1.790(1.659-3.759)$ & 0.0006 \\
\hline$\$ 25,000$ to 29,999 & 28 & 26 & $48.15 \%$ & $1.565(1.174-3.283)$ & 0.0005 \\
\hline$\$ 30,000$ to 49,999 & 41 & 19 & $38.00 \%$ & $2.496(1.258-5.045)$ & 0.0052 \\
\hline$\$ 50,000$ to 74,999 & 26 & 6 & $18.75 \%$ & $6.065(2.416-16.952)$ & $<.0001$ \\
\hline$\$ 75,000$ or more & 25 & 4 & $13.79 \%$ & $2.578(0.0235-0.087)$ & $<.0001$ \\
\hline \multicolumn{6}{|l|}{ Health insurance } \\
\hline Yes & 211 & 112 & $34.67 \%$ & $1.242(1.161-2.363)$ & $<0.001$ \\
\hline No & 36 & 132 & $78.57 \%$ & & \\
\hline \multicolumn{6}{|l|}{ Health conditions } \\
\hline Obese & 101 & 103 & $50.49 \%$ & $.654(0.357-.954)$ & $<0.001$ \\
\hline Not obese & 145 & 139 & $48.94 \%$ & & \\
\hline \multicolumn{6}{|l|}{ Age } \\
\hline$\geq 50$ & 97 & 33 & $74.61 \%$ & $0.317(0.214-0.469)$ & $<0.001$ \\
\hline$<50$ & 150 & 212 & $58.56 \%$ & & \\
\hline \multicolumn{6}{|l|}{ Affordability to visit doctor } \\
\hline No & 70 & 149 & $68.03 \%$ & $0.290(0.205-0.411)$ & $<0.001$ \\
\hline Yes & 167 & 79 & $32.11 \%$ & & \\
\hline
\end{tabular}


Table 3: The association between selected socioeconomic variables and use of breast-self exam in four BBC (Barbour, Green, Macon and Wilcox) of Alabama.

\begin{tabular}{|c|c|c|c|c|c|}
\hline \multirow[t]{2}{*}{ Variable } & \multicolumn{5}{|c|}{ Use of Self Breast Exam } \\
\hline & yes & no & $\%$ not using & OR $(95 \% \mathrm{CI})$ & $\chi^{2}$ (p-value) \\
\hline \multicolumn{6}{|l|}{ Education } \\
\hline - Grades 1 through 8 (elementary) & 4 & 7 & $63.63 \%$ & $0.2383(0.1073-0.3692)$ & $<.0001$ \\
\hline Grades 9 through 11 (some high school) & 24 & 25 & $51.02 \%$ & $0.1387(0.0604-0.2170)$ & $<.001$ \\
\hline - Grade 12 or GED (high school graduate) & 92 & 47 & $33.81 \%$ & $1.1129(1.0683-1.2482)$ & $<.0001$ \\
\hline $\begin{array}{l}\text { - College } 1 \text { year to } 3 \text { years (some college or } \\
\text { technical school) }\end{array}$ & 129 & 39 & $23.21 \%$ & 1.1215(1.0451-1.1636) & $<.0001$ \\
\hline College 4 years or more (college graduate) & 67 & 27 & $28.72 \%$ & $1.145(1.0518-1.3457)$ & $<.0001$ \\
\hline Graduate school & 26 & 14 & $35.00 \%$ & $1.266(1.2164-3.3125)$ & $<.0001$ \\
\hline \multicolumn{6}{|l|}{ Family income } \\
\hline$\$ 9,999$ or under & 29 & 69 & $70.40 \%$ & $0.21(0.0656-0.3606)$ & $<.0001$ \\
\hline$\$ 10,000$ to 14,999 & 30 & 24 & $44.44 \%$ & $0.12(0.0385-0.2142)$ & $<.0001$ \\
\hline$\$ 15,000$ to 19,999 & 41 & 25 & $37.87 \%$ & $0.17(0.0450-0.2541)$ & $<.0001$ \\
\hline$\$ 20,000$ to 24,999 & 54 & 22 & $28.94 \%$ & $1.40(1.1859-2.7590)$ & 0.0006 \\
\hline$\$ 25,000$ to 29,999 & 39 & 7 & $15.22 \%$ & $1.56(0.7480-3.2830)$ & 0.0005 \\
\hline$\$ 30,000$ to 49,999 & 66 & 14 & $17.50 \%$ & $1.49(0.5580-3.0450)$ & 0.0052 \\
\hline$\$ 50,000$ to 74,999 & 46 & 14 & $23.33 \%$ & $1.17(1.4160-2.0450)$ & $<.0001$ \\
\hline \multicolumn{6}{|l|}{ Health insurance } \\
\hline Yes & 252 & 100 & $28.41 \%$ & $1.21(1.0140-2.3980)$ & $<0.001$ \\
\hline No & 93 & 57 & $38.00 \%$ & & \\
\hline \multicolumn{6}{|l|}{ Health conditions } \\
\hline Obese & 110 & 286 & $72.22 \%$ & $0.37(0.1794-0.5636)$ & 0.0005 \\
\hline Not obese & 56 & 47 & $45.63 \%$ & & \\
\hline \multicolumn{6}{|l|}{ Age } \\
\hline$\geq 50$ & 44 & 89 & $66.91 \%$ & $0.0586(0.214-0.469)$ & $<0.001$ \\
\hline$<50$ & 257 & 113 & $30.54 \%$ & & \\
\hline \multicolumn{6}{|l|}{ Affordability to visit doctor } \\
\hline No & 147 & 78 & $34.67 \%$ & $0.1780(0.0065-0.3496)$ & $<0.001$ \\
\hline Yes & 182 & 69 & $27.49 \%$ & & \\
\hline
\end{tabular}

Table 4: Results of logistic regression analysis (presented as adjusted odds ratio and $95 \%$ confidence interval).

\begin{tabular}{|c|c|c|c|c|c|c|}
\hline \multirow[b]{2}{*}{ Effect } & \multicolumn{3}{|c|}{ Usage rate of mammography exam } & \multicolumn{3}{|c|}{ Usage rate of self-breast exam } \\
\hline & Adjusted OR & $95 \% \mathrm{CI}$ & & Adjusted OR & $95 \% \mathrm{C}$ & \\
\hline Age & 0.455 & 0.304 & 0.723 & 0.57 & 0.384 & 0.765 \\
\hline \multicolumn{7}{|l|}{ Family income /year } \\
\hline$\$ 10,000$ to 14,999 & 0.844 & 0.422 & 1.688 & 0.651 & 0.299 & 1.414 \\
\hline$\$ 15,000$ to 19,999 & 2.536 & 1.109 & 5.799 & 0.994 & 0.458 & 2.158 \\
\hline$\$ 20,000$ to 24,999 & 3.564 & 1.433 & 8.867 & 1.339 & 1.162 & 2.865 \\
\hline$\$ 25,000$ to 29,999 & 1.773 & 1.1805 & 3.906 & 1.1806 & 1.069 & 1.759 \\
\hline$\$ 30,000$ to 49,999 & 1.896 & 1.869 & 4.136 & 1.687 & 1.785 & 3.624 \\
\hline$\$ 50,000$ to 74,999 & 1.494 & 1.196 & 3.747 & 3.134 & 1.196 & 8.215 \\
\hline$\$ 75,000$ or more & 1.204 & 1.168 & 3.097 & 2.854 & 1.022 & 7.973 \\
\hline Health Insurance(no vs yes) & 0.779 & 0.453 & 0.834 & 0.306 & 0.173 & 0.542 \\
\hline
\end{tabular}

Note: $. \mathrm{OR}=$ odds ratio; $\mathrm{CI}=$ confidence interval (Wald confidence limits).

* Models are adjusted for Health Insurance (No insurance vs have insurance), Income(less than $\$ 9,999$ as reference vs. above $\$ 10,000$ with $\$ 5,000$ interval until $\$ 75,000$ and above), and age.

\section{Discussion}

Considering Breast cancer mortality rates, it can be safely stated that health disparities exist in rural and minority population (16). There are 24 BBC (Black Belt counties) in rural southern Alabama. Out of these 24 BBCs, four were chosen for this study: Barbour, Greene, Macon, and Wilcox counties (21).

In a previous study, higher death rates from breast cancer among African-American women were found to be strongly associated with various socio-demographic attributes (income, age, and severity of health condition) (19). But the focus of our study was to find out, how some socio-demographic factors (health insurance, income, age and severity of health condition and affordability to visit doctor) play role in creating disparities in breast cancer screening (mammography) and BSE which are thought to have pivotal role in the early diagnosis and thereby reduction of breast cancer mortality (7). Accordingly, our results indicate that African American women in rural black belt counties who have health insurance would be more likely to report higher screening rates compared to uninsured African American women (65.33\% vs. $34.67 \%$; $\mathrm{P}<0.001$, Table 2). A similar effect of having 
health insurance was seen regarding whether or not women conducted BSE $(71.59 \%$ vs. $28.441 \%$; $\mathrm{P}<0.001$ Table 3). Overall, our study suggests a need to make health insurance affordable to all women so that they can reap the benefits of mammography screening and BSE.

Rahman et al. (23) previously documented a noteworthy pattern of association between median annual income per zip code of residence and adherence to mammography screening guidelines. Espey DK et. al. (15) showed over half of American Indian or Alaska Native individuals have potentially low access and availability of health care services and also lower utilization of screening services because rates of poverty for them are three times higher than those for non-Hispanic whites (22). Similarly, our study showed that higher income level has a positive correlation $(\mathrm{P}<0.0001$; (Table 2) with mammography screening in African American women in rural Alabama. Also, reported BSE by the African American women in rural Alabama showed strong association $(\mathrm{P} \leq 0.0001)$ with income levels according to our study (Table 3).

Our study further demonstrated that removing financial barriers alone is not enough to influence the optimum utilization of mammography screening. Several factors, in combination or singly, affect the utilization of mammography screening service in the rural Alabama. According to the National Cancer Institute's [NCI] Surveillance, Epidemiology, and End Results [SEER] Program for the years 2007 through 2009 , the risk of breast cancer in women increases with the increase in age ( $\geq 50$ years ) and body weight. While searching for that angle, in our study, we found a negative correlation (i.e. as the age increases women are using fewer mammograms) (Table 2) between African American women aged 50 years and older and rate of mammography screening in rural Alabama $(P<0.0001)$. Similarly, women aged 50 years and older are less likely to do BSE than women aged $<50$ years $(\mathrm{P}<0.001)$ (Table 3$)$. On the other hand, $72.22 \%$ of obese women aged 50 years and older reported not using mammography screening. This finding indicates that although post-menopausal obese women are relatively at higher risk of breast cancer, they are showing up more for less mammography screening $(\mathrm{P}<.0001)$ and BSE $(\mathrm{P}<.0001)$. It is established that obesity is an important risk factor for Breast cancer (26).

According to Meguerditchian An. et. al and O'Malley et al. $(24,25)$ physician recommendation can increase cancer screening rates among women, and that holds true for all types of screening rates and race or ethnicity. But Lee Anne Roman et. al. (23) gives us another perspective in addition to the above; their study shows that African American women with more health literacy risk score (i.e., lower health literacy) have reduced odds of mammogram (23). Their study also found a significant association between decreased odds of BSE and lack of doctor mammogram recommendation. In Our study, we addressed this issue from a different point of view. We showed that African American women who could afford to visit a family doctor had higher rates of mammography screening $(67.89 \%$ vs. $32.11 \%)$ compared to those who can't afford (Table 2). We also found that higher educational attainment among African American women in rural Alabama had a positive correlation with mammography screening that is statistically significant $(\mathrm{P}<0.0001)$. Again higher educational attainment among African American women in rural Alabama had a positive correlation with breast-self exam $(\mathrm{P}<0.001)$. All these indicate that, if, by appropriate means, we can improve access to health care (such as increase affordability and educational awareness) among African-American women residing in rural Alabama; they would use breast cancer screening services appropriately. It seems therefore that eliminating screening barriers, for early detection and treatment of breast cancer, is critical in reducing breast cancer health disparity in African American women of rural Alabama.

Reducing breast cancer mortality among African-American women is an important challenge in rural Alabama. We conclude from our study that uninsured and less educated African American women utilize fewer mammography screening for breast cancer. The link between breast cancer screening and health insurance and the ability to afford a family doctor visit may explain some of the disparities. Therefore, our study suggests that if we improve access to health care facilities for female residents of these counties, they will use cancer screening services appropriately and timely manner. Also improving educational attainment will provide some knowledge about BSE, which will greatly contribute to lower mortality rates for breast cancer.

\section{Acknowledgments}

This work is partially supported by NCMHD SC21MD000102 and NCIR RCMI 5 G12RR03059, National Institutes of Health (NIH).The authors would like to thank all faculty, staffs and students of College of Veterinary Medicine, Nursing and Allied Health (CVMNAH), Tuskegee University.

\section{Competing Interests}

The authors declared that we don't have any conflicts of interest to disclose. 


\section{References}

1. [Internet] US Census Bureau. US Interim Projections by Age, Sex, Race, and Hispanic Origin: 2000-2050. http://www.census.gov/ipc/www/ usinterimproj/.

2. Jing L, Gabriel H, Dihua Y, et al. Breast Cancer Metastasis: Challenges and Opportunities. Cancer Res 2009; 69:4951.

3. Lawson HW, Henson R, Bobo JK, Kaeser MK. Implementing recommendations for the early detection of breast and cervical cancer among low-income women. MMWR Recomm Rep. 2000;49:37-55.

4. Gøtzsche PC, Jørgensen KJ. Screening for breast cancer with mammography. Cochrane Database Syst Rev. 2013;6:CD001877.

5. Allen JD, Bluethmann SM, Sheets M, Opdyke KM, Gates-Ferris K, Hurlbert M, Harden E. Women's responses to changes in U.S. Preventive Task Force's mammography screening guidelines: results of focus groups with ethnically diverse women. BMC Public Health. 2013;13:1169.

6. Kosters JP, Gotzsche PC. Regular self-examination or clinical examination for early detection of breast cancer. Cochrane Database Syst Rev. 2003;(2):CD003373..

7. Chiarelli AM, Majpruz V, Brown P, Thriault M, Shumak R, Mai V. The contribution of clinical breast examination to the accuracy of breast screening. J Natl Cancer Inst.2009, 101(18):1236-43.

8. Heba M. et. al. Barriers to breast cancer screening among a sample of Egyptian females. J Family Community Med. 2014; 21(2): 119-124.

9. David D. Disparities in breast cancer outcomes between Caucasian and African American women: a model for describing the relationship of biological and nonbiological factors. Breast Cancer Res. 2013; 15(3): 208.

10. Tice A, Kerlikowske K. Screening and prevention of breast cancer in primary care. Prim Care. 2009 Sep;36(3):533-58.

11. de la Crus, Sarfaty M, Wender C. An update on breast cancer screening and prevention. Prim Care. 2014 Jun;41(2):283-306.

12. Alabama department of Public Health: Selected Indicators of Rural Health Status in Alabama. Alabama Rural Health Report.2003. 3(1): 1-14

13. [Internet] Susan G. Komen for the Cure: Disparities in Breast Cancer Screening. http://ww5.komen.org/BCDisparities.html

14. Moorman G, Jones A, Millikan C, Hall J, and Newman B. Race, anthropometric factors, and stage at diagnosis of breast cancer. American Journal of Epidemiology. 2000;153:3

15. McDonald C. Addressing disparities and the disproportionate burden of cancer. Cancer. 2001. 91(suppl): 195-198.

16. Jemal A, Murray T, Ward E, Samuels A, Tiwari C, Ghafoor A, Feuer J, Thun J..2005. Cancer statistics. CA Cancer. J Clin. 2005; 55:10-30.

17. [Internet] National Cancer Institute (NCI): Fact Sheet. Cancer health disparities. http://www.cancer.gov/about-nci/organization/crchd/cancer-healthdisparities-fact-sheet

18. Otero-Sabogal R, Owens D, Canchola J, Golding JM, Tabnak F, Fox P. Mamograhpy rescreening women of diverse ethnicities: patient, provider, and health care system factors. J Health Care Poor Underserved. 2004 Aug;15(3):390-412

19. Vernon W, Laville A, Jackson L. Participation in breast screening programs: a review. Soc Sci Med. 1990;30(10):1107

20. Weiss L, Soong J, Partridge E, Carpenter J, Bryant B, Waterbor W. Cancer incidence among predominantly black, rural-poor populations in southern states. South Med J. 1997 Oct:90(10):986-92.

21. Nedra L, Theresa W, and Edward P. Cancer Health Disparities: What We Have Done. Am J Med Sci. 2008; 335(4): 254-259

22. Smedley BD, Stith AY, Nelson AR, Unequal treatment: confronting racial and ethnic disparities in health care. Institute of Medicine (US) Committee on Understanding and Eliminating Racial and Ethnic Disparities in Health Care; Washington (DC): The National Academies Press(US); 2003.

23. Saleh R, Mark D, and Brent J. Shelton A Theory-Based Model for Predicting Adherence to Guidelines for Screening Mammography among Women Age 40 and Older. Int J Canc Prev. 2005;2(3): 169-179.

24. Malley M, Earp J, Hawley S, Schell M, Mathews $\mathrm{H}$, and Mitchell J. The association of race/ethnicity, socioeconomic status, and physician recommendation for mammography: who gets the message about breast cancer screening? Am J Public Health.2001. 91(1): 49-54.

25. Meguerditchian N, Dauphinee D, Girard N, et al. Do physician communication skills influence screening mammography utilization? BMC Health Serv Res 2012;12:219.

26. [Internet] National Cancer Institute: Breast cancer risk in American women, 2012. http://www.cancer.gov/cancertopics/factsheet/detection/ probability-breast-cancer

27. Pace LE, He Y, Keating NL. Trends in mammography screening rates after publication of the 2009 US Preventive Services Task Force recommendations. Cancer. 2013;119(14):2518-23. 